\title{
Módulo elástico como ferramenta para avaliação da hidratação da magnésia e do processamento de concretos refratários
}

\author{
(Elastic modulus as a tool for magnesia hydration and \\ refractory castables processing evaluation)
}

\author{
T.M.Souza ${ }^{1}$ M.A.L. Braulio ${ }^{I}$, P. Bonadia ${ }^{2}$, V.C.Pandolfelli ${ }^{I}$ \\ ${ }^{1}$ Grupo de Engenharia e Microestrutura de Materiais - GEMM, Departamento de Engenharia de Materiais, \\ Universidade Federal de S. Carlos, Rod. Washington Luiz, km 235, C.P. 676, S. Carlos, SP 13565-905 \\ ${ }^{2}$ Magnesita Refratários S.A., Centro de Pesquisas e Desenvolvimento, Praça Louis Ensch 240, Contagem, MG \\ uaitiago@gmail.com,vicpando@power.ufscar.br
}

\begin{abstract}
Resumo
Considerando-se as dificuldades para a utilização de $\mathrm{MgO}$ em concretos refratários, técnicas anti-hidratação têm sido propostas com o objetivo de minimizar os efeitos deletérios causados pela reação da magnésia com a água. Em paralelo, surge a necessidade de investigar novas metodologias que permitam melhor avaliar os danos causados pela hidratação. Neste sentido, uma técnica promissora consiste no acompanhamento do módulo de Young durante as etapas de cura e secagem dos concretos. No presente trabalho, concretos refratários contendo magnésia cáustica ou sínter de $\mathrm{MgO}$ foram avaliados por meio do acompanhamento do módulo elástico utilizandose o método de ressonância de barras. A avaliação das etapas iniciais de processamento (cura e secagem) dos concretos por meio do uso desta técnica apresentou-se como uma alternativa adequada para detecção dos efeitos causados pela hidratação do MgO. Os resultados obtidos também destacam que, em comparação com outras técnicas comumente empregadas, as medidas do módulo elástico permitem delinear com maior precisão a evolução da microestrutura em função do tempo, além de detectar antecipadamente os danos relacionados à formação de brucita, garantindo-se assim maior sensibilidade no monitoramento de tal reação.
\end{abstract}

Palavras-chave: módulo elástico, hidratação da magnésia, concretos refratários.

\begin{abstract}
Considering the difficulties related to the use of $\mathrm{MgO}$ in refractory castables, anti-hydration techniques have been proposed, in order to minimize the drawbacks as a result of the magnesia hydration. In parallel, new methodologies should be investigated, aiming better evaluation of the damage caused by the hydration. In this context, a promising technique is the Young's modulus measurement during curing and drying processing steps of refractory castables. In this work, caustic magnesia-containing castables and deadburned magnesia-containing ones were evaluated by following the elastic modulus profile using the resonance bar method. The evaluation of the initial stages of castables processing (curing and drying) using this technique seemed to be a proper route to detect $\mathrm{MgO}$ hydration. The results also highlighted that, compared with usual methods, the elastic modulus measurements results a better sample evolution profile as a function of time and earlier detection of the damage associated with brucite formation.
\end{abstract}

Keywords: elastic modulus, magnesia hydration, refractory castables.

\section{INTRODUÇÃO}

Concretos refratários contendo magnésia $(\mathrm{MgO})$ apresentam elevada refratariedade e boa resistência ao ataque por escórias básicas. Em temperaturas elevadas, a combinação de magnésia e alumina pode resultar na formação de espinélio $\left(\mathrm{MgAl}_{2} \mathrm{O}_{4}\right)$ in situ, que apresenta alto ponto de fusão $\left(2135^{\circ} \mathrm{C}\right)$ e resistência ao ataque químico e ao choque térmico adequadas. Entretanto, o emprego de teores elevados de $\mathrm{MgO}$ ( $>6 \%$ em peso) em concretos refratários ainda é um desafio para indústria refratarista, pois, ao entrar em contato com a água (líquida ou vapor) a magnésia se hidrata facilmente, resultando na formação de brucita $\mathrm{Mg}(\mathrm{OH})_{2}$. Devido a diferença de densidade entre a magnésia
$\left(\varrho_{\mathrm{MgO}}=3,5 \mathrm{~g} / \mathrm{cm}^{3}\right)$ e o hidróxido de magnésio $\left(\mathrm{Q}_{\mathrm{Mg}(\mathrm{OH})_{2}}=\right.$ $\left.2,4 \mathrm{~g} / \mathrm{cm}^{3}\right)$, este fenômeno de hidratação é acompanhado por expansão volumétrica. Como os concretos apresentam elevada densidade à verde e, portanto baixa porosidade, esta expansão pode não ser apropriadamente acomodada, gerando tensões de tração no corpo, causando a formação de trincas ou até a completa desintegração do material [1-3]. Sendo assim, a utilização de $\mathrm{MgO}$ em concretos refratários tem sido limitada ao uso de partículas grosseiras (diâmetro médio $>40 \mu \mathrm{m}$ ) e em teores menores que 6\%-p [4-6].

Um dos fatores que influenciam a hidratação da magnésia é a sua reatividade. Partindo-se da calcinação da magnesita $\left(\mathrm{MgCO}_{3}\right)$, dois tipos de magnésia com reatividades distintas podem ser obtidas, a magnésia cáustica (MC) e o sínter 
de magnésia (SM) [7]. A MC, obtida em temperaturas relativamente inferiores $\left(850-1000{ }^{\circ} \mathrm{C}\right)$, é altamente reativa (alta área superficial) e é principalmente aplicada na área da agricultura. Já o SM (1800-2000 $\left.{ }^{\circ} \mathrm{C}\right)$, que possui menor reatividade, é utilizado principalmente na indústria de refratários, justamente devido à sua menor tendência à hidratação. A princípio, a utilização de magnésia cáustica em concretos refratários é indesejável, uma vez que suas características favorecem a hidratação do $\mathrm{MgO}$ e podem acarretar considerável redução de fluidez durante a etapa de moldagem do concreto. No entanto, o controle sobre essas dificuldades teria um grande impacto nas aplicações industriais, pois a utilização de fontes de magnésia mais reativas favoreceria a formação de espinélio em temperaturas inferiores às usuais. Devido ao grande potencial tecnológico de concretos refratários contendo $\mathrm{MgO}$, técnicas antihidratação (TAH) têm sido propostas para reduzir os efeitos deletérios da adição de $\mathrm{MgO}$ e também para viabilizar o uso de magnésias cáusticas [8-10]. Em paralelo, há a necessidade de se investigar novas metodologias que permitam avaliar com maior precisão os danos causados pela hidratação. Neste sentido, uma técnica promissora consiste no acompanhamento do módulo de Young, já utilizada para a avaliação da pega de cimentos e concretos para construção civil [11] e também para determinação da integridade mecânica de refratários [12], como por exemplo, após ciclos de choque térmico [13].

A evolução do módulo de Young foi avaliada em função do tempo de cura para pastas (cimento e água) e argamassas [11]. A correlação encontrada entre as propriedades mecânicas e químicas durante a cura indicou aspectos importantes das reações de hidratação do cimento e revelou uma grande sensibilidade do módulo elástico à formação de novas ligações químicas entre as partículas. Observouse ainda que o módulo elástico aumenta rapidamente no período inicial de cura, devido à ligação gradual entre as partículas, e mais lentamente no período posterior, em decorrência do preenchimento de poros. Os avanços no emprego do módulo elástico para caracterizar materiais para construção civil serviram como motivação para a aplicação desta técnica na avaliação da hidratação de cimentos e da cura de concretos refratários, possibilitando a otimização do tempo entre a aplicação e a desmoldagem de produtos monolíticos [14, 15]. Adicionalmente, medidas do módulo de Young também foram utilizadas para estudar a hidratação de tijolos comerciais de magnésia quando expostos ao vapor de água. De acordo com estes resultados, durante o estágio inicial de hidratação do $\mathrm{MgO}$, a expansão causada pela formação de brucita é acomodada pela porosidade da estrutura, proporcionando um aumento do módulo elástico e uma redução da porosidade [16]. Após atingir a capacidade máxima de acomodação, a expansão torna-se crítica e as tensões geradas superam a resistência mecânica do material, o que resulta na formação de trincas, aumento da porosidade e diminuição do módulo elástico. Sendo assim, os resultados apresentados anteriormente para a hidratação do cimento, cura de concretos refratários e hidratação de tijolos de magnésia [14-16] indicam que o módulo de Young é uma ferramenta útil para a caracterização da hidratação da magnésia. No entanto, não foi encontrado na literatura um estudo em que se utiliza esta técnica para investigar a hidratação do $\mathrm{MgO}$ durante a cura e secagem de concretos refratários alumina-magnésia.

Com relação às técnicas utilizadas para a determinação do módulo de Young, os métodos dinâmicos mostramse mais adequadas, uma vez que são não-destrutivos e envolvem a solicitação do material aplicando-se tensões relativamente baixas, evitando-se as contribuições nãoelásticas [12]. Neste caso, os mesmos corpos-de-prova podem ser utilizados para medidas subseqüentes, reduzindose as possíveis variações relacionadas à mistura e moldagem, e permitindo uma avaliação mais precisa das alterações na microestrutura. Entre os métodos dinâmicos, a ressonância de barras é a técnica mais indicada para caracterização de concretos refratários devido ao alto fator de amortecimento, à presença de partículas grosseiras (agregados), e ao nível elevado de porosidade e microtrincas, comuns nestes materiais [12]. Diante deste cenário e considerando-se a necessidade de novas metodologias para a investigação da hidratação do $\mathrm{MgO}$ em concretos refratários, o presente trabalho teve por objetivo a avaliação da hidratação da magnésia, durante a cura e secagem de concretos refratários, utilizando-se medidas do módulo de Young obtidas por meio da técnica de ressonância de barras. $\mathrm{O}$ efeito da hidratação nas propriedades elásticas foi determinado para concretos contendo cimento de aluminato de cálcio (CAC) ou não (sem ligante), e para duas fontes distintas de $\mathrm{MgO}$ (SM e MC). As vantagens da utilização desta técnica são apresentadas por meio de uma comparação com as medidas de resistência mecânica, porosidade, expansão volumétrica aparente (EVA) [3] e ensaios de termogravimetria.

\section{MATERIAIS E MÉTODOS}

Duas fontes de $\mathrm{MgO}$ foram empregadas para a avaliação da hidratação nos concretos refratários. Um sínter de magnésia (SM) e uma fonte de magnésia cáustica (MC) com área superficial $0,9 \mathrm{~m}^{2} / \mathrm{g}$ e $25,3 \mathrm{~m}^{2} / \mathrm{g}$, respectivamente. As propriedades físicas e a composição química das fontes de $\mathrm{MgO}$ estão indicadas na Tabela I. Suspensões aquosas foram preparadas visando-se avaliar as diferenças no grau de hidratação entre as fontes de $\mathrm{MgO}$ e a temperatura de decomposição do $\operatorname{Mg}(\mathrm{OH})_{2}$. A proporção magnésia/água utilizada foi de 1:2. Primeiramente as suspensões foram agitadas por $5 \mathrm{~h}$ à temperatura ambiente em um misturador de bancada e depois por mais $2 \mathrm{~h}$ a $90{ }^{\circ} \mathrm{C}$, para acelerar o processo de hidratação da magnésia. Em seguida, foram secas por $24 \mathrm{~h}$ a $110{ }^{\circ} \mathrm{C}$ para remoção da água livre, permitindo-se a determinação do perfil de secagem e do grau de hidratação por meio de análises termogravimétricas, técnica que será detalhada nesta seção.

Composições de concreto refratário vibrado de alta alumina e contendo 6\%-p de magnésia (magnésia cáustica ou sínter de magnésia, Magnesita Refratários S.A., Brasil), 
Tabela I - Propriedades físicas e composição química das fontes de magnésia selecionadas. [Table I - Physical properties and chemical composition of the selected magnesia sources.]

\begin{tabular}{cccccccccc}
\hline \multirow{2}{*}{ Fonte de magnésia } & \multicolumn{3}{c}{ Propriedades físicas } & \multicolumn{6}{c}{ Composição química (\%-peso) } \\
\cline { 2 - 9 } & $\mathrm{D}_{50}(\mu \mathrm{m})$ & $\mathrm{SSA}\left(\mathrm{m}^{2} / \mathrm{g}\right)$ & $\mathrm{MgO}$ & $\mathrm{CaO}$ & $\mathrm{SiO}_{2}$ & $\mathrm{Al}_{2} \mathrm{O}_{3}$ & $\mathrm{Fe}_{2} \mathrm{O}_{3}$ & $\mathrm{MnO}$ & $\mathrm{CaO} / \mathrm{SiO}_{2}$ \\
\hline $\mathrm{MC}$ & 16 & 25,3 & 98,4 & 0,88 & 0,17 & 0,05 & 0,42 & 0,10 & 5,18 \\
$\mathrm{SM}$ & 9 & 0,9 & 98,2 & 0,84 & 0,33 & 0,12 & 0,41 & 0,13 & 2,54 \\
\hline
\end{tabular}

7\%-p de alumina reativa (CL370, Almatis, EUA), 1\%-p de microssílica (971U, Elkem, Noruega), e 0\%-p ou 6\%-p de cimento de aluminato de cálcio (Secar 71, Kerneos, França) foram utilizadas nos testes. Uma formulação contendo 6\%-p de cimento aluminoso e sem magnésia foi também utilizada como referência para os concretos contendo CAC. Aluminas tabulares ( $\mathrm{d} \leq 6 \mathrm{~mm}$, Almatis, EUA) constituíram os agregados e a dispersão foi garantida adicionando-se 0,2\%-p de um aditivo dispersante eletroestérico (Basf, Alemanha). A formulação foi desenvolvida por meio do modelo de empacotamento de Alfred $(\mathrm{q}=0,26)$ e o teor de água para cada composição foi ajustado de acordo com um alvo de fluidez inicial sob vibração de $80 \%$, visando-se uma moldagem adequada. A Tabela II apresenta as principais características das composições avaliadas.

Após moldagem, os concretos foram curados a 50 ${ }^{\circ} \mathrm{C}$ em uma câmara climática (Vöetsch 2020, Alemanha) com umidade relativa de $80 \%$. O processo de cura foi acompanhado ao longo de 7 dias por meio de medidas do módulo de Young, resistência mecânica, porosidade aparente e expansão volumétrica aparente (EVA). Também foi medida durante a cura a perda de água associada à secagem. Adicionalmente, após 1 dia de cura, amostras foram secas a $110{ }^{\circ} \mathrm{C}$ e tratadas termicamente $\left(300\right.$ ou 350 e $\left.650{ }^{\circ} \mathrm{C}\right) \mathrm{e}$ suas propriedades avaliadas por meio do módulo de Young, resistência mecânica e porosidade. O teor de água livre ou quimicamente ligada em cada temperatura foi também determinado. Finalmente, após 1 e 7 dias de cura, foi feito o ensaio de termogravimetria para determinação do perfil de secagem.

Para avaliação do módulo de Young os concretos foram moldados na forma de barras retangulares com dimensões $\sim 150 \times 25 \times 25 \mathrm{~mm}^{3}$. Após $3 \mathrm{~h}$ de cura os corpos-deprova foram cuidadosamente desmoldados e as medidas do módulo elástico foram iniciadas. O módulo de Young foi avaliado por meio da técnica de ressonância de barras em equipamento Scanelastic (ATCP, Brasil), de acordo com a norma ASTM C 1198-91. O arranjo experimental deste ensaio consiste na excitação da amostra e na deteç̧ão de seu espectro de vibração por meio da utilização de transdutores piezoelétricos. A excitação é realizada em uma faixa de freqüências suficiente para obtenção das freqüências naturais de ressonância das barras e, a partir dos modos normais de vibração calcula-se o módulo de Young, utilizando as equações de Pickett, que relacionam o módulo elástico, as freqüências naturais de vibração e as dimensões da amostra [17]. Para freqüência fundamental de flexão das barras o módulo de Young é dado por:

$$
\mathrm{E}=0,9465 \frac{\mathrm{mf}_{\mathrm{f}}^{2}}{\mathrm{~b}} \times \frac{\mathrm{L}^{3}}{\mathrm{t}^{3}} \times \mathrm{T}_{1}
$$

na qual E é o módulo de Young $(\mathrm{Pa}), \mathrm{m}$ é a massa $(\mathrm{g}), \mathrm{b}$ a largura (mm), L o comprimento (mm), t a espessura ( $\mathrm{mm})$, $\mathrm{f}_{\mathrm{f}}$ a freqüência fundamental de ressonância da barra em flexão $(\mathrm{Hz})$ e $\mathrm{T}_{1}$ o fator de correção para o modo de flexão fundamental que leva em consideração a espessura finita da

Tabela II - Composições dos concretos refratários estudados.

[Table II - Refractory castables evaluated compositions.]

\begin{tabular}{|c|c|c|c|c|c|}
\hline \multirow{3}{*}{ Matérias primas } & \multicolumn{2}{|c|}{$\%$-peso } & \multicolumn{2}{|c|}{$\%$-peso } & \multirow{2}{*}{$\frac{\% \text {-peso }}{\text { Sem MgO }}$} \\
\hline & \multicolumn{2}{|c|}{ Magnésia cáustica (MC) } & \multicolumn{2}{|c|}{$\begin{array}{l}\text { Sínter de } \mathrm{MgO} \\
(\mathrm{SM})\end{array}$} & \\
\hline & MC-OCAC* & MC-6CAC* & SM-0CAC* & SM-6CAC* & 6CAC* \\
\hline Alumina tabular $(\mathrm{d} \leq 6 \mathrm{~mm})$ & 80 & 80 & 80 & 80 & 80 \\
\hline Alumina reativa (CL370) & 7 & 7 & 7 & 7 & 7 \\
\hline Microssílica (971 U) & 1 & 1 & 1 & 1 & 1 \\
\hline Magnésia (MC ou SM) & 6 & 6 & 6 & 6 & 0 \\
\hline $\begin{array}{c}\text { Cimento de aluminato de cálcio } \\
\text { (Secar 71) }\end{array}$ & 0 & 6 & 0 & 6 & 6 \\
\hline Alumina tabular $(\mathrm{d}<45 \mu \mathrm{m})$ & 6 & 0 & 6 & 0 & 6 \\
\hline Água & 5,8 & 5,9 & 4,1 & 4,2 & 4,2 \\
\hline
\end{tabular}

*MC-OCAC: magnésia cáustica-0\%-p de cimento; MC-6CAC: magnésia cáustica-6\%-p de cimento; SM-0CAC: sínter de magnésia-0\%-p de cimento; SM-6CAC: sínter de magnésia - 6\%-p de cimento; 6CAC: 6\%-p de cimento e sem $\mathrm{MgO}$. 
barra e a razão de Poisson.

A resistência mecânica, durante a cura e após a secagem, foi medida por compressão diametral segundo a norma ASTM C 496-90 em um equipamento MTS (modelo 810, EUA) sob taxa de aplicação de carga constante e igual a 40 N/s. A tensão de ruptura foi calculada a partir da equação abaixo:

$$
\sigma_{R}=2 x\left(\frac{P_{\text {max }}}{\pi L D}\right)
$$

na qual $\sigma_{\mathrm{R}}$ é a tensão de ruptura $(\mathrm{MPa}), \mathrm{P}_{\text {max }}$ é a força de ruptura (N), L é a altura (m) e D o diâmetro da amostra (m).

A porosidade aparente das amostras foi avaliada de acordo com a norma ASTM C 830, utilizando querosene como fluido de imersão.

$\mathrm{O}$ teste de expansão volumétrica aparente (EVA) consiste em medir as dimensões de amostras cilíndricas (40 $\mathrm{mm}$ de diâmetro e $40 \mathrm{~mm}$ de altura) durante a exposição em determinadas condições de temperatura e umidade [3]. O cálculo da EVA é realizado considerando as seguintes equações:

$$
\begin{aligned}
& \mathrm{V}_{\mathrm{i}}=\mathrm{h}_{\mathrm{i}} \mathrm{x} \pi \mathrm{x} \frac{\left(\mathrm{d}_{\mathrm{i}}-2 \mathrm{t}\right)^{2}}{4} \\
& \operatorname{EVA}(\%)=100 \times\left(\frac{\mathrm{V}_{\mathrm{E}}-\mathrm{V}_{0}}{\mathrm{~V}_{0}}\right)
\end{aligned}
$$

na qual $\mathrm{V}_{\mathrm{i}}$ é o volume das amostras em um dado tempo $\left(\mathrm{mm}^{3}\right), \mathrm{h}_{\mathrm{i}}$ a altura $(\mathrm{mm}), \mathrm{d}_{\mathrm{i}} \mathrm{o}$ diâmetro $(\mathrm{mm})$ e t a espessura da parede do molde ( $\mathrm{mm})$. A expansão volumétrica aparente (equação D) é obtida por meio da diferença entre o volume inicial da amostra $\left(\mathrm{V}_{0}\right)$ e o volume após a expansão $\left(\mathrm{V}_{\mathrm{E}}\right)$.

Durante a cura, a perda de água associada à secagem foi determinada com a equação:

$$
\mathrm{W}_{\text {acumulada }}=100 \times\left(\frac{\mathrm{M}_{0}-\mathrm{M}_{\mathrm{f}}}{\mathrm{M}_{0}}\right)
$$

na qual $\mathrm{W}_{\text {acumulada }}\left(\%\right.$-p) é perda de água acumulada, $\mathrm{M}_{0} \mathrm{a}$ massa da amostra (g) no início da cura e $\mathrm{M}_{\mathrm{f}}$ a massa final (g) após cada intervalo de tempo.

A quantidade de água eliminada após cada tratamento térmico foi calculada por meio do parâmetro $\mathrm{W}_{\mathrm{D}}(\%-\mathrm{p})$ :

$$
\mathrm{W}_{\mathrm{D}}=100 \times\left(\frac{\mathrm{M}_{0}-\mathrm{M}_{\mathrm{f}}}{\mathrm{M}_{0}}\right)
$$

na qual $M_{i}$ e $M_{f}$ são os valores da massa (g) antes e após o tratamento térmico, respectivamente. Primeiramente as amostras foram secas por $24 \mathrm{~h}$ a $110{ }^{\circ} \mathrm{C}$ e em seguida queimadas a $300{ }^{\circ} \mathrm{C}$ (para os concretos sem cimento) ou $350{ }^{\circ} \mathrm{C}$ (para os concretos com cimento) e $650{ }^{\circ} \mathrm{C}$, utilizando-se uma taxa de aquecimento de $1^{\circ} \mathrm{C} / \mathrm{min}$ e um patamar de 5 h. O grau de hidratação do $\mathrm{MgO}$ foi avaliado por meio da comparação entre a massa de água liberada durante a secagem (relativa à decomposição do $\mathrm{Mg}(\mathrm{OH})_{2}$ ) e a quantidade teórica de água necessária para hidratar toda magnésia presente nos concretos. $\mathrm{W}_{\mathrm{H}}$ foi calculado utilizando-se a equação [18]:

$\mathrm{W}_{\mathrm{H}}(\%)=100 \times\left(\frac{2,24 \times \mathrm{M}_{350-600{ }^{\circ} \mathrm{C}}}{\mathrm{M}_{\mathrm{Mg} 0}}\right)$

na qual 2,24 refere-se à razão entre a massa de 1 mol de $\mathrm{MgO}$ e $1 \mathrm{~mol}$ de $\mathrm{H}_{2} \mathrm{O}$ (de acordo com a reação estequiométrica), $\mathrm{M}_{350-600^{\circ} \mathrm{C}}$ é a massa de água relativa à decomposição da brucita e $\mathrm{M}_{\mathrm{MgO}}$ a massa de magnésia da amostra (referente a porcentagem de $\mathrm{MgO}$ da formulação). Neste caso, considerou-se que após o tratamento térmico a $350{ }^{\circ} \mathrm{C}$ por $5 \mathrm{~h}$, praticamente todos os hidratos de cimento foram decompostos $[3,19]$. Para os concretos sem cimento utilizou-se o intervalo $300-650{ }^{\circ} \mathrm{C}$.

Para os ensaios de termogravimetria, as amostras foram previamente secas por $24 \mathrm{~h}$ a $110{ }^{\circ} \mathrm{C}$ para remoção da água livre. Os testes foram conduzidos até $800{ }^{\circ} \mathrm{C}$ em um equipamento de análise termogravimétrica [19], com uma taxa de aquecimento de $10{ }^{\circ} \mathrm{C} / \mathrm{min}$. A perda de massa cumulativa $(\mathrm{W})$ e a velocidade de secagem $(\mathrm{dW} / \mathrm{dt})$ foram calculadas conforme as equações abaixo:

$$
\begin{aligned}
& \mathrm{W}(\%)=100 \times\left(\frac{\mathrm{M}_{0}-\mathrm{M}}{\mathrm{M}_{0-} \mathrm{M}_{\mathrm{F}}}\right) \\
& \left(\frac{\mathrm{dW}}{\mathrm{dt}}\right)_{\mathrm{i}}=\left(\frac{\mathrm{W}_{(\mathrm{i}+10)}-\mathrm{W}_{(\mathrm{i}-10)}}{\mathrm{t}_{(\mathrm{i}+10)}-\mathrm{t}_{(\mathrm{i}-10)}}\right)
\end{aligned}
$$

nas quais $\mathrm{M}_{0}$ é a massa inicial (g), $\mathrm{M}$ é a massa instantânea (g) registrada em um tempo $t_{i}(s)$ e $M_{f}$ é a massa final da amostra $(\mathrm{g})$. A taxa de secagem é dada em $\% / \mathrm{min}$.

\section{RESULTADOS E DISCUSSÃO}

\section{Avaliação das fontes de $\mathrm{MgO}$ utilizadas}

Os resultados de perda de massa para as suspensões de $\mathrm{SM} / \mathrm{H}_{2} \mathrm{O}$ e $\mathrm{MC} / \mathrm{H}_{2} \mathrm{O}$ são apresentados Fig. 1. De acordo com a reação de decomposição da brucita (equação $\mathrm{J}$ ), esperase uma perda de massa próxima de $30 \%$, caso todo o $\mathrm{MgO}$ presente reaja com água.

$$
\mathrm{Mg}(\mathrm{OH})_{2} \rightarrow \mathrm{MgO}+\mathrm{H}_{2} \mathrm{O}
$$

As perdas de massa totais obtidas para a magnésia cáustica e para o sínter correspondem a $27 \%$ e $\sim 14 \%$, respectivamente, revelando que para as condições utilizadas a MC reage quase totalmente, enquanto que o SM é bem menos reativo. A decomposição da brucita ocorre na mesma faixa de temperatura para as duas fontes de $\mathrm{MgO}$, acima 


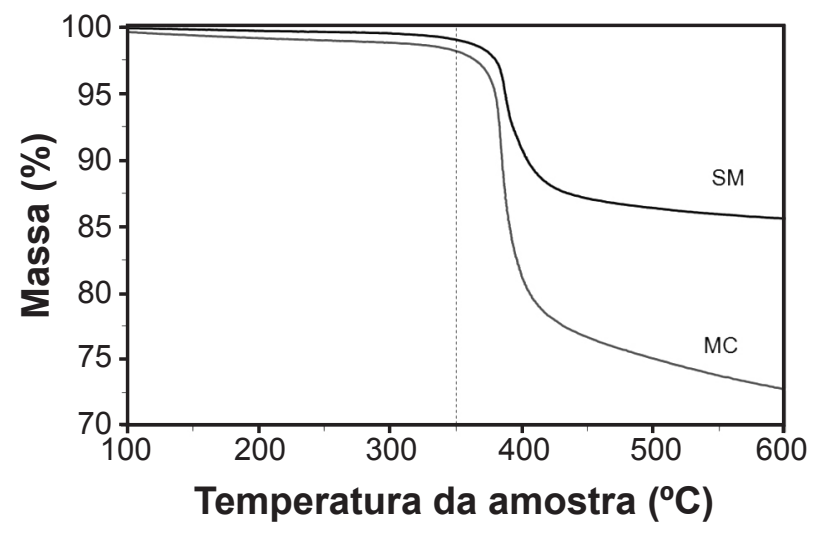

Figura 1: Perda de massa para as suspensões de magnésia cáustica (MC) ou sínter de magnésia (SM).

[Figure 1: Mass loss curve for caustic magnesia (MC) and deadburned magnesia (SM) suspensions.]

de $350{ }^{\circ} \mathrm{C}$, indicando que tratamentos térmicos abaixo de $350{ }^{\circ} \mathrm{C}$ não são suficientes para iniciar a sua decomposição, nas condições de ensaio estabelecidas.

Apesar da perda de massa total dar uma boa estimativa da quantidade de hidróxido de magnésio formado, observase na Fig. 1 (abaixo de $350{ }^{\circ} \mathrm{C}$ ) a saída de uma pequena quantidade de água livre remanescente. Sendo assim, para melhor avaliar a hidratação do $\mathrm{MgO}$ (considerando apenas a perda de massa entre $350-600^{\circ} \mathrm{C}$ ) e realizar uma comparação mais efetiva entre as fontes de magnésia, utilizou-se a medida do grau de hidratação (equação G). Os resultados indicam que, para as condições utilizadas nas suspensões, a MC não reagiu totalmente e seu grau de hidratação foi de aproximadamente $80 \%$ enquanto para o sínter foi inferior a $40 \%$.

\section{Avaliação da cura de concretos contendo magnésia}

A Fig. 2a apresenta os resultados do módulo elástico (MOE) e da resistência mecânica em função do tempo de cura (a $50{ }^{\circ} \mathrm{C}$, em ambiente saturado em água) para dois concretos contendo magnésia cáustica, com 6\%-p (MC6CAC) ou sem cimento (MC-0CAC). Para a composição MC-6CAC, tanto o módulo elástico quanto a resistência mecânica aumentam no período inicial, atingem a máxima intensidade e em seguida decrescem até o sétimo dia de cura. Enquanto o módulo elástico começa a decrescer após o segundo dia de cura, a redução da resistência mecânica só é observada após o terceiro dia. Estes resultados indicam que apesar das técnicas de MOE e resistência mecânica serem equivalentes as medidas do módulo elástico são mais práticas, uma vez que as mesmas amostras podem ser usadas durante todo período de cura, além de permitir delinear com maior precisão a evolução da microestrutura do concreto em função do tempo de cura. Adicionalmente, como a resistência mecânica é principalmente dependente do tamanho do defeito e do acabamento superficial, observa-se um desvio padrão muito maior que do MOE, que não é perceptível nas figuras devido a escala usada. Quando a fonte de $\mathrm{MgO}$ empregada
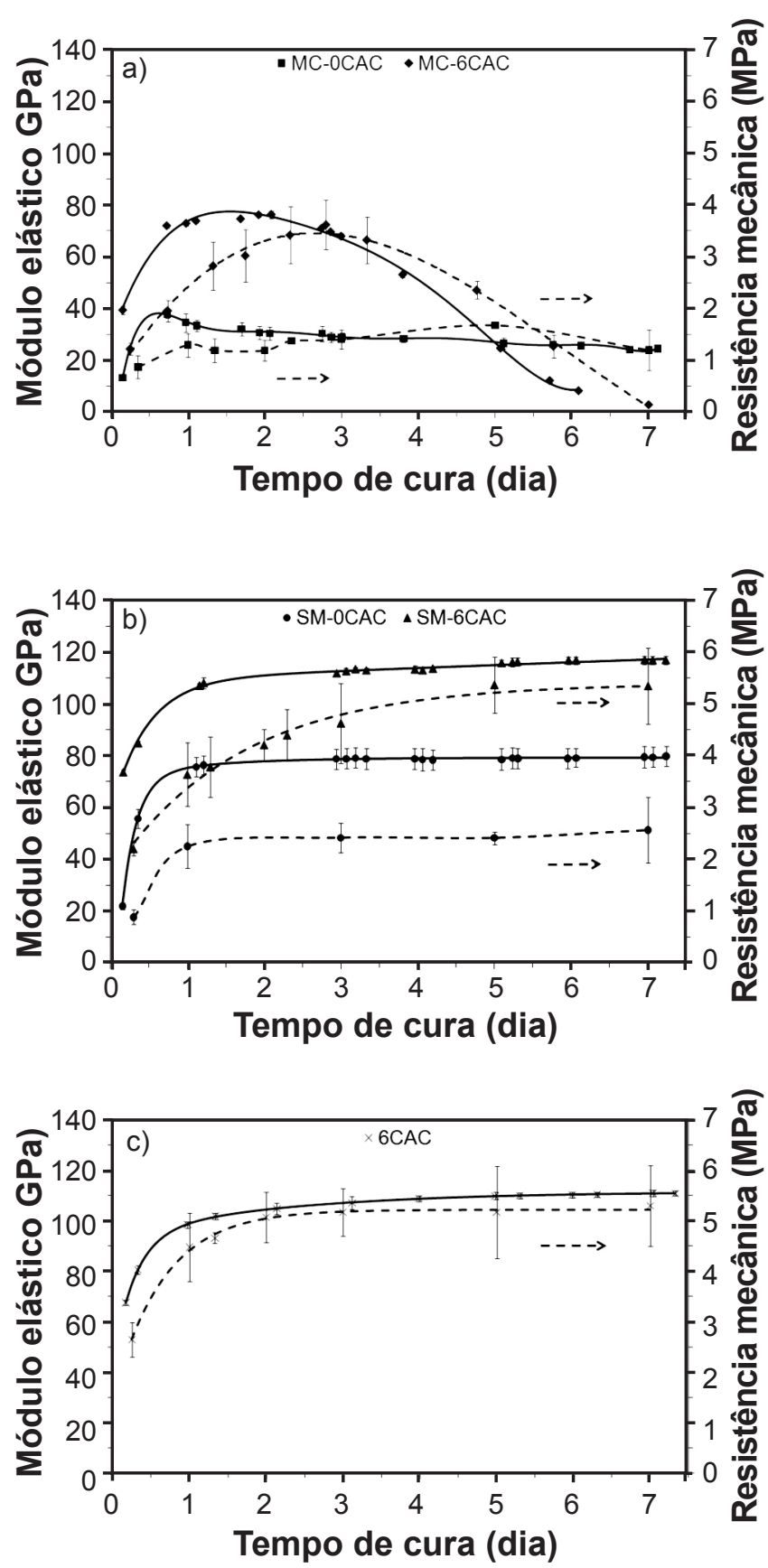

Figura 2: Módulo elástico e resistência mecânica (compressão diametral) em função do tempo de cura. a) concretos contendo $\mathrm{MC}$, sem cimento (MC-0CAC) e com cimento (MC-6CAC); b) concretos contendo SM, sem cimento (SM-0CAC) e com cimento (SM-6CAC); c) concreto contendo cimento e sem $\mathrm{MgO}$ (6CAC).

[Figure 2: Elastic modulus and mechanical strength (diametral compression) as a function of curing time. a) MC-containing castables without cement (MC-OCAC) and with cement (MC6CAC); b) SM-containing castables without cement (SM-OCAC) and with cement $(S M-6 C A C) ; c)$ cement-containing castable without $\mathrm{MgO}(6 \mathrm{CAC})$.]

é menos reativa, como no caso do sínter de magnésia (SM), observa-se um aumento inicial nos valores do MOE e da resistência mecânica, que atingem a intensidade máxima e permanecem praticamente constantes até o sétimo dia de 
cura (Fig. 2b). Os resultados apresentados na Fig. 2 indicam dois comportamentos distintos para a evolução do módulo elástico em função do tempo de cura de concretos refratários contendo magnésia. No primeiro deles, o aumento rápido do MOE seguido de queda indica que a expansão associada à hidratação da magnésia não foi acomodada pela estrutura (Fig. 2a). Já no segundo, o aumento gradativo do MOE até o sétimo dia de cura mostra que não ocorreram danos devido à formação de brucita (Fig. 2b). Um dos motivos para tal é o menor grau de hidratação observado no SM (Fig. 1b).

O aumento e a redução dos valores do módulo de Young durante a cura estão relacionados principalmente às alterações nas freqüências fundamentais de ressonância flexural, na densidade e nas dimensões das amostras (equação A). À medida que novas fases são desenvolvidas, devido à hidratação do cimento e da magnésia, ligações entre as partículas são continuamente formadas e ocorre uma redução na porosidade devido ao preenchimento ocasionado na formação de hidratos de cimento e brucita, resultando em um aumento das freqüências de ressonância e, conseqüentemente, no módulo de Young. Por outro lado, a geração de trincas contribui para a redução do módulo elástico dos concretos. Além da fonte de magnésia, outro fator importante que diferencia o comportamento entre os concretos estudados é a presença de cimento de aluminato de cálcio. Durante a hidratação do CAC ocorre a precipitação e o crescimento de cristais de hidratos, responsáveis pela formação de uma rede que permite a ligação entre as partículas e confere maior resistência mecânica aos corpos. Por isto os concretos contendo CAC (MC-6CAC e SM-6CAC) apresentam maior resistência mecânica do que as composições semelhantes sem cimento (MC-0CAC e SM-0CAC). De forma geral, quanto maior a hidratação do CAC, maior a resistência mecânica e menor a porosidade do concreto. No entanto, apesar da superior resistência mecânica permitir maior expansão sem que ocorram danos, a menor porosidade diminui a possibilidade de acomodação adequada da brucita na estrutura do concreto [3]. Uma composição contendo 6\%-p de CAC e sem magnésia foi utilizada como referência para avaliar o efeito da hidratação do $\mathrm{MgO}$ no módulo elástico e na resistência mecânica, os resultados são apresentados na Fig. 2c. Comparando-se os concretos 6CAC (Fig. 2c) e SM-6CAC (Fig. 2b), ambos com o mesmo teor de água (4,2\%-p), observa-se um pequeno aumento do MOE para o SM-6CAC indicando que a formação de novas ligações devido à hidratação do $\mathrm{MgO}$ contribuem para o aumento da rigidez. Por outro lado, para a resistência mecânica o desvio padrão é grande, tornando difícil avaliar o efeito da formação de brucita. Entretanto, a adição de magnésia também confere uma contribuição extra para a resistência mecânica do concreto, quando sua hidratação não gera microtrincas [20]. De acordo com estes resultados, para as composições contendo CAC, o aumento do módulo elástico e da resistência mecânica deve-se principalmente a hidratação do cimento além de uma contribuição menor devido à formação de brucita. No caso das composições sem cimento (MC-0CAC e SM-0CAC, Fig. 2a e b), a magnésia atua como ligante e sua contribuição para o aumento do MOE e da resistência mecânica é maior, pois forma-se uma quantidade superior de brucita, que pode ser suficiente até mesmo para posteriormente destruir o corpo, como verificado no concreto MC-0CAC. Para as composições contendo MC e SM, (até o segundo e terceiro dia de cura, respectivamente) observa-se um aumento da porosidade enquanto a expansão volumétrica aparente ainda é nula, o que está associado principalmente à formação de brucita, que possui menor densidade que a magnésia (Fig. 3a e b). Como pode ser observado na Fig. 3a, os concretos MC0CAC e MC-6CAC apresentam uma redução do módulo elástico acompanhada por um aumento da porosidade e da expansão volumétrica aparente. A maior quantidade de água exigida para a mistura adequada dos concretos MC0CAC e MC-6CAC resultou em maior nível de porosidade, menores rigidez e resistência mecânica, indicando que a combinação de maior reatividade e propriedades mecânicas inferiores ocasionou a formação de trincas. Entretanto, o aumento da resistência mecânica para a composição contendo CAC contribui para um atraso na queda do MOE (Fig. 2a). Com relação aos concretos contendo SM, após terceiro dia de cura, a porosidade permanece praticamente constante e não ocorre expansão (Fig. 3b), o que é coerente com os resultados do MOE (Fig. 2b). O concreto sem $\mathrm{MgO}$ (6CAC, Fig. 3c) também não apresenta expansão e sua porosidade permanece praticamente constante após o primeiro dia de cura. Adicionalmente, comparandose as composições SM-6CAC e 6CAC observa-se que a presença de sínter de magnésia resultou em menores níveis de porosidade devido à formação de brucita, enquanto na presença de magnésia cáustica ocorre o contrário (MC6CAC).

Os resultados da perda de água acumulada em função do tempo de cura são apresentados na Fig. 4. A água eliminada durante a cura, medida como perda de massa, pode ser associada principalmente à evaporação da água livre e à saída de água devido à conversão de hidratos metaestáveis do cimento aluminoso, $\mathrm{C}_{2} \mathrm{AH}_{8}$ e $\mathrm{CAH}_{10}$, para o hidrato estável $\mathrm{C}_{3} \mathrm{AH}_{6}\left(3 \mathrm{CaO} \cdot \mathrm{Al}_{2} \mathrm{O}_{3} \cdot 6 \mathrm{H}_{2} \mathrm{O}\right)$ [21]. De acordo com os resultados experimentais as maiores perdas de água são observadas até o terceiro dia de cura e após este período a massa das amostras permanece constante ou sofre pequenas alterações. Para as condições de cura adotadas, a maior perda de água livre com o tempo de cura é observada no final do primeiro dia e é significativamente superior para concretos contendo MC. Apesar da magnésia cáustica hidratar mais e por isto consumir mais água, a dificuldade relacionada à dispersão de suas partículas exigiu um consumo maior de água durante o processamento $(5,8$ a $5,9 \%$ em peso). Por outro lado, uma quantidade maior de água ficou retida nos concretos MC-6CAC e SM-6CAC, em relação às formulações semelhantes sem cimento, devido à hidratação do CAC. Além disso, para o concreto MC-6CAC (Fig. 4), observa-se que entre o terceiro e sétimo dia de cura houve uma redução na perda de água 

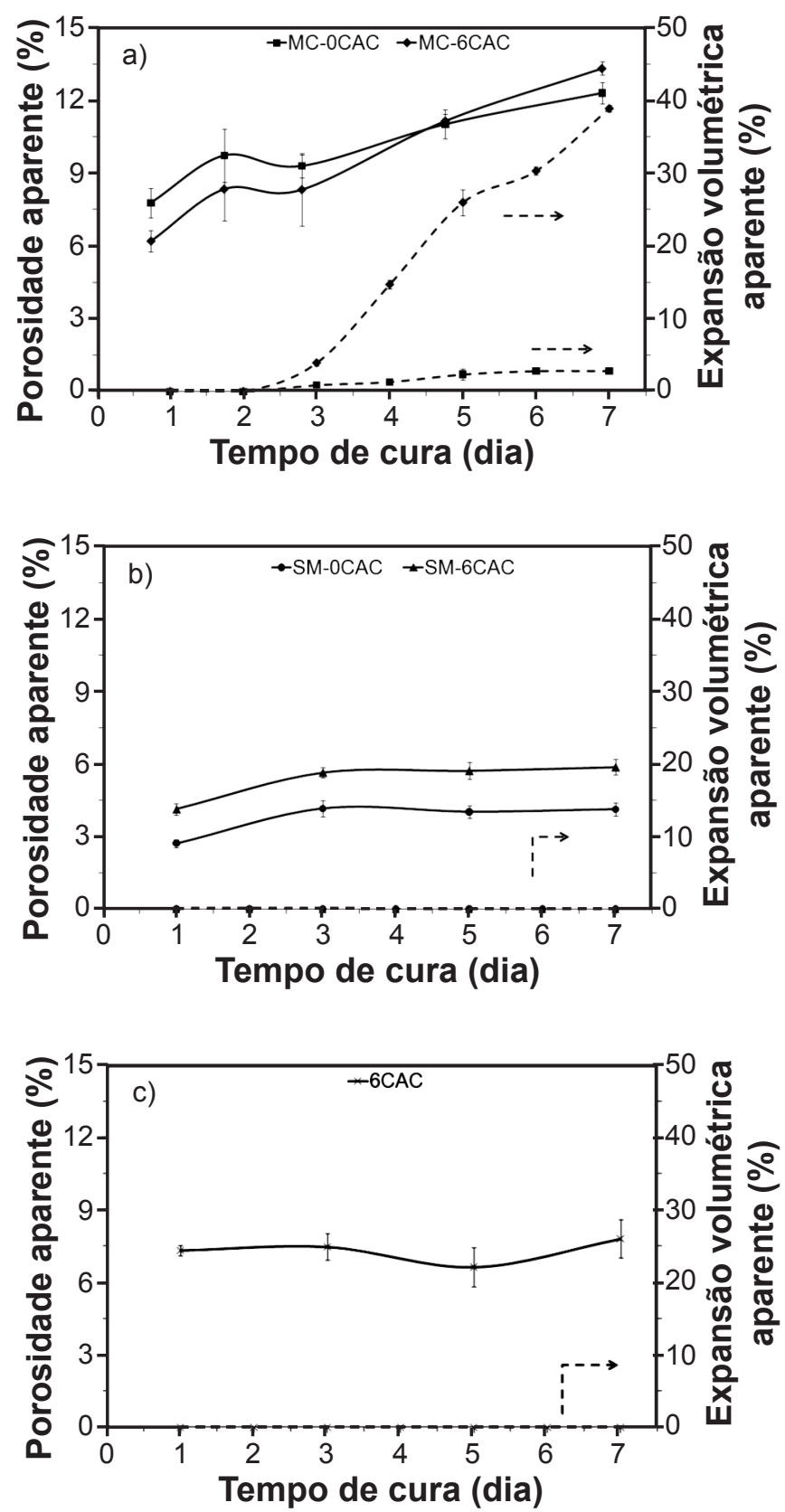

Figura 3: Porosidade aparente e expansão volumétrica aparente em função do tempo de cura. a) concretos contendo $\mathrm{MC}$, sem cimento (MC-0CAC) e com cimento (MC-6CAC); b) concretos contendo $\mathrm{SM}$, sem cimento (SM-0CAC) e com cimento (SM-6CAC); c) concreto contendo cimento e sem $\mathrm{MgO}$ (6CAC).

[Figure 3: Apparent porosity and apparent volumetric expansion as a function of curing time. a) MC-containing castables without cement (MC-OCAC) and with cement (MC-6CAC); b) SMcontaining castables without cement (SM-OCAC) and with cement (SM-6CAC); c) cement-containing castable without $\mathrm{MgO}(6 C A C)$.]

acumulada, o que pode ser resultado do trincamento das amostras (Fig. 5) e conseqüente exposição dessas novas superfícies ao vapor de água, possibilitando a hidratação da magnésia e o ganho de massa. $\mathrm{O}$ aspecto visual do corpo de prova mostrado na Fig. 5 reforça esta idéia, pois a face do concreto apoiada sobre o substrato ficou menos exposta

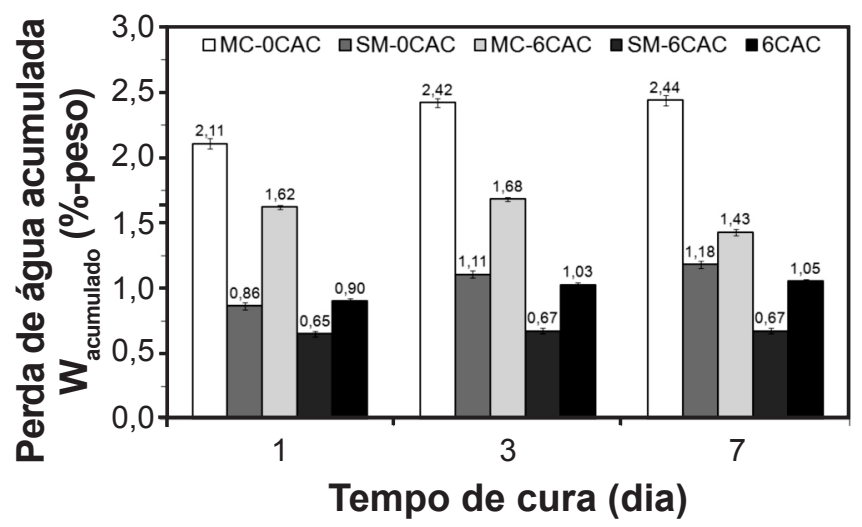

Figura 4: Perda de água acumulada $\left(\mathrm{W}_{\text {acumulada }}\right)$ em função do tempo de cura para os concretos sem cimento (MC-0CAC e SM-0CAC) e com cimento (MC-6CAC, SM-6CAC e 6CAC).

[Figure 4: Water loss $\left(W_{\text {acumulated }}\right.$ ) as a function of curing time for free-cement castables (MC-OCAC and SM-OCAC) and cementcontaining castables (MC-6CAC, SM-6CAC and 6CAC).]

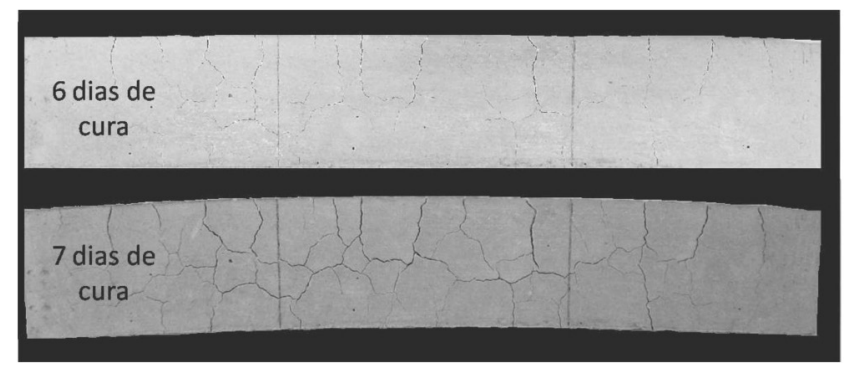

Figura 5: Aspectos visuais do concreto MC-6CAC após 6 e 7 dias de cura a $50{ }^{\circ} \mathrm{C}$ em ambiente saturado. Corpo de prova com dimensões aproximadas de $150 \times 25 \times 25 \mathrm{~mm}^{3}$.

[Figure 5: Visual aspects of MC-6CAC castable after 6 and 7 days of curing at $50{ }^{\circ} \mathrm{C}$ in humid environment. Sample dimensions of roughly $150 \times 25 \times 25 \mathrm{~mm}^{3}$.]

ao vapor de água e apresentou menor trincamento, ou seja, menor hidratação do $\mathrm{MgO}$, causando o empenamento da amostra. Os resultados da perda de água também indicam que uma quantidade maior de água é eliminada durante a cura para o concreto $6 \mathrm{CAC}$ em relação ao concreto SM6CAC, o que é resultado da hidratação da magnésia (Fig. 4).

Apesar de ter sido observado um aumento da porosidade no início da cura, não ocorre simultaneamente uma redução do MOE para todas as composições, indicando que nesse período a formação de novas ligações químicas (devido à hidratação do CAC e da magnésia) contribui mais significativamente para a rigidez. $\mathrm{O}$ concreto $\mathrm{MC}$ 6CAC apresenta expansão e redução da rigidez simultânea enquanto para a composição MC-0CAC, antes do final do primeiro dia, observa-se uma queda do módulo elástico e expansão nula (Fig. 2a e 3a). De acordo com estes resultados, utilizando-se as medidas do MOE torna-se possível detectar, de forma antecipada, pequenos danos causados pela hidratação do $\mathrm{MgO}$ que não podem ser observados por meio da expansão (EVA) ou da resistência mecânica. 
Avaliação da secagem de concretos contento magnésia

Os resultados do módulo de Young apresentados indicam que após 1 dia de cura apenas a composição MCOCAC apresentou queda do MOE devido à hidratação do $\mathrm{MgO}$ (Fig. 2). No entanto, após secagem a $110{ }^{\circ} \mathrm{C}$, notase uma redução do módulo elástico para composição $\mathrm{MC}$ 0 CAC e MC-6CAC em relação as amostras úmidas devido à formação de trincas (Fig. 6a). Tal resultado indica o efeito do vapor de água em acelerar a hidratação do $\mathrm{MgO}$ ressaltando que os danos são mais evidentes na etapa de secagem que na de cura. A vaporização da água livre aumenta o nível de pressão dentro dos concretos, podendo resultar em danos microestruturais $[19,22]$, que podem ser ainda mais pronunciados quando os corpos possuem baixa resistência mecânica, como no caso dos concretos sem cimento.

Para as composições contendo MC, a queda do MOE (Fig. 6a) e o aumento da porosidade (Fig. 7) durante a secagem são resultado da remoção da água e da formação de trincas, observadas visualmente na Fig. 8. Apesar do trincamento, durante a secagem a $110{ }^{\circ} \mathrm{C}$ a resistência mecânica aumentou devido à formação de hidratos estáveis do cimento aluminoso [21]. Entre $110{ }^{\circ} \mathrm{C}$ e $650{ }^{\circ} \mathrm{C}$ um aumento adicional da porosidade e pequenas variações no $\mathrm{MOE}$ e na resistência mecânica foram observadas, devido à propagação das trincas e à decomposição dos hidratos. Estes resultados ressaltam a importância da utilização do MOE para a detecção de danos que não podem ser observados visualmente mas que são indicados como uma queda no valor do módulo elástico. Sendo assim, a avaliação do módulo de Young é ainda mais relevante para o controle da etapa de secagem dos concretos contendo magnésia, uma vez que neste estágio ocorre um aumento na velocidade de hidratação do $\mathrm{MgO}$.

Um comportamento distinto foi observado para os concretos contendo SM, onde houve aumento do MOE, da resistência mecânica e da porosidade após secagem por 1 dia a $110^{\circ} \mathrm{C}$ (Figs. 6b e 7). Comparando-se com o concreto SM0CAC, a composição SM-6CAC mostrou menor aumento de porosidade devido a formação de hidratos de cimento e à saída de uma quantidade menor de água livre. Para secagem em temperaturas mais elevadas, $300{ }^{\circ} \mathrm{C}$ ou $350{ }^{\circ} \mathrm{C}$ e $650{ }^{\circ} \mathrm{C}$, ocorre um aumento adicional da porosidade e uma redução do MOE e da resistência mecânica devido à decomposição dos hidratos. A composição 6CAC, apresentou comportamento semelhante ao concreto SM-6CAC, um aumento do módulo elástico após secagem a $110{ }^{\circ} \mathrm{C}$ (em relação as amostras úmidas) e posterior redução do MOE devido a decomposição dos hidratos de cimento, acompanhado por um aumento da porosidade (Figs. 6c e 7). Adicionalmente, comparandose com os concretos contendo MC, os concretos contendo SM apresentam pequenas mudanças na porosidade após o tratamento térmico a $300{ }^{\circ} \mathrm{C}$ ou $350{ }^{\circ} \mathrm{C}$, o que é um indicativo da quantidade menor de brucita formada.

Durante a secagem dos concretos refratários, em temperaturas inferiores a $100{ }^{\circ} \mathrm{C}$, ocorre a saída da água fisicamente adsorvida principalmente por meio da evaporação. Com o aumento da temperatura (acima de
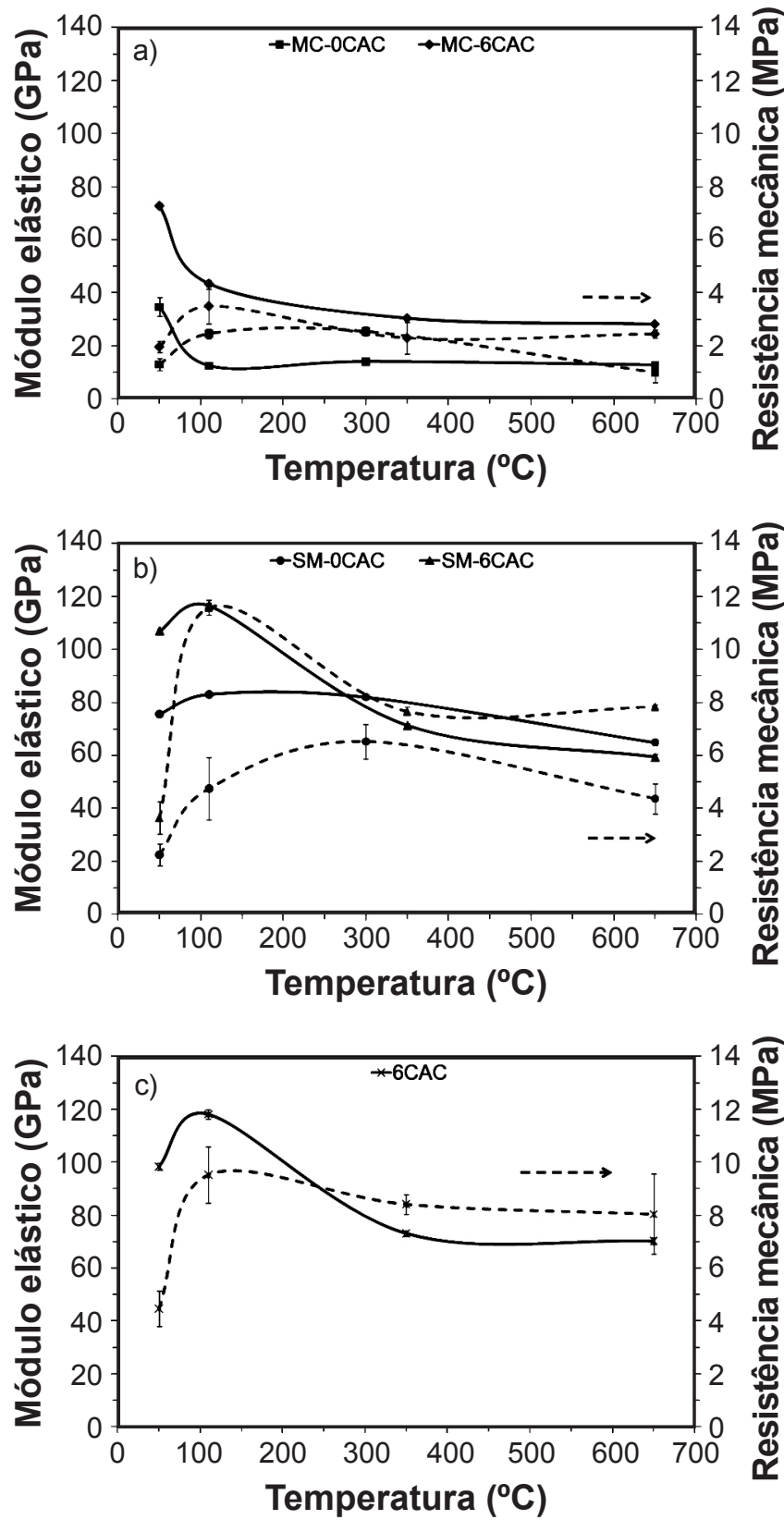

Figura 6: Módulo elástico e resistência mecânica após 1 dia de cura e após secagem a $110{ }^{\circ} \mathrm{C}, 300^{\circ} \mathrm{C}$ ou $350{ }^{\circ} \mathrm{C}$ e $650{ }^{\circ} \mathrm{C}$. a) concretos contendo $\mathrm{MC}$, sem cimento (MC-0CAC) e com cimento (MC6CAC); b) concretos contendo SM, sem cimento (SM-OCAC) e com cimento (SM-6CAC); c) concreto contendo cimento e sem $\mathrm{MgO}$ (6CAC).

[Figure 6: Elastic modulus and mechanical strength after 1 day of curing and drying at $110{ }^{\circ} \mathrm{C}, 300{ }^{\circ} \mathrm{C}$ or $350{ }^{\circ} \mathrm{C}$ and $650{ }^{\circ} \mathrm{C}$. a) MC-containing castables without cement (MC-OCAC) and with cement $(M C-6 C A C)$; b) SM-containing castables without cement (SM-0CAC) and with cement (SM-6CAC); c) cement-containing castable without $\mathrm{MgO}$ (6CAC).]

$100{ }^{\circ} \mathrm{C}$ ), a água livre é removida da estrutura por meio da ebulição, ocorrendo uma redução da distância média entre as partículas e um aumento da resistência mecânica em relação as propriedades do concreto à verde [23]. Somado a isto, a formação de $\mathrm{AH}_{3}\left(\mathrm{Al}_{2} \mathrm{O}_{3} \cdot 3 \mathrm{H}_{2} \mathrm{O}\right)$ e $\mathrm{C}_{3} \mathrm{AH}_{6}$ 


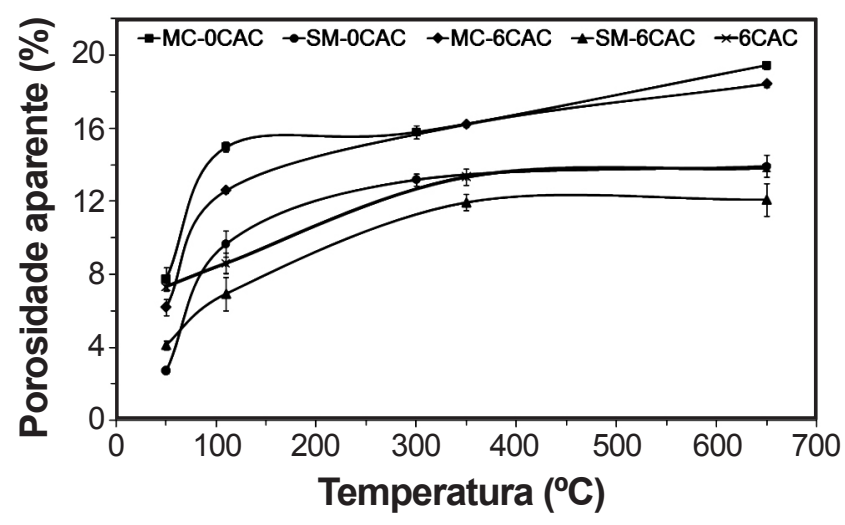

Figura 7: Porosidade aparente após 1 dia de cura e após secagem a $110^{\circ} \mathrm{C}, 300^{\circ} \mathrm{C}$ ou $350{ }^{\circ} \mathrm{C}$ e $650^{\circ} \mathrm{C}$ para os concretos sem cimento (MC-0CAC e SM-0CAC) e com cimento (MC-6CAC, SM-6CAC e 6CAC).

[Figure 7: Apparent porosity after 1 day of curing and drying at $110{ }^{\circ} \mathrm{C}, 300{ }^{\circ} \mathrm{C}$ or $350{ }^{\circ} \mathrm{C}$ and $650{ }^{\circ} \mathrm{C}$ for free-cement castables (MC-OCAC and SM-OCAC) and cement-containing castables (MC6CAC, $S M-6 C A C$ and $6 C A C)$.]

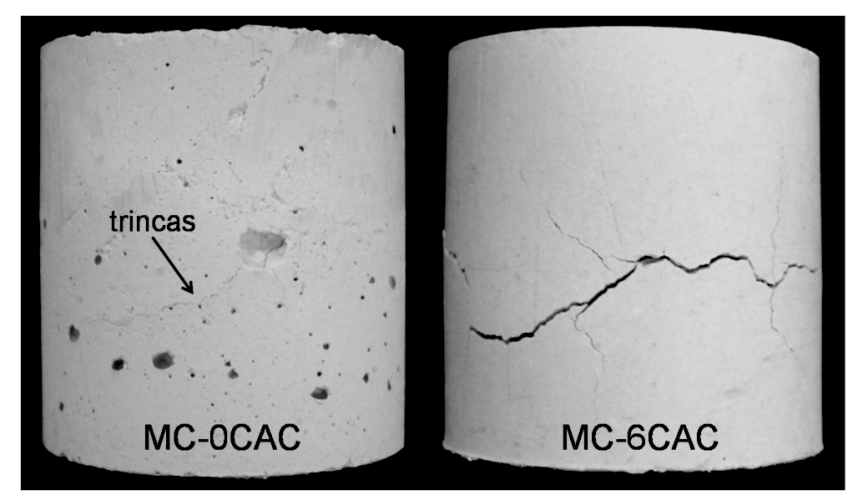

Figura 8: Aspectos visuais dos concretos MC-0CAC e MC-6CAC após um dia de cura $\left(50{ }^{\circ} \mathrm{C}\right)$ e um dia de secagem a $110{ }^{\circ} \mathrm{C}$. Corpo de prova cilíndrico com dimensões aproximadas de $40 \mathrm{~mm}$ x $40 \mathrm{~mm}$. [Figure 8: Visual aspects of MC-OCAC and MC-6CAC castables afterl day of curing $\left(50{ }^{\circ} \mathrm{C}\right)$ and 1 day of drying at $110{ }^{\circ} \mathrm{C}$. Cylindrical sample with dimensions of roughly $40 \mathrm{~mm} \times 40 \mathrm{~mm}$.]

(3CaO. $\left.\mathrm{Al}_{2} \mathrm{O}_{3} \cdot 6 \mathrm{H}_{2} \mathrm{O}\right)$ também contribuem para o aumento da resistência mecânica [21]. Entre $210{ }^{\circ} \mathrm{C}$ e $360{ }^{\circ} \mathrm{C}$ ocorre a decomposição dos hidratos do cimento aluminoso [21], e entre $350{ }^{\circ} \mathrm{C}$ e $600{ }^{\circ} \mathrm{C}$ do hidróxido de magnésio [3], aumentando a porosidade e reduzindo a resistência mecânica. Considerando-se a eliminação gradual de água da estrutura dos concretos, tratamentos térmicos foram realizados em temperaturas distintas, visando-se avaliar a quantidade de água eliminada em cada estágio. Primeiramente, após 1 dia de cura a $50{ }^{\circ} \mathrm{C}$, as amostras foram secas a $110{ }^{\circ} \mathrm{C}$ por $24 \mathrm{~h}$ e a quantidade de água removida avaliada de acordo com a equação F. Em seguida as mesmas amostras foram submetidas a um tratamento térmico (taxa de aquecimento $1{ }^{\circ} \mathrm{C} / \mathrm{min}$ ) a $300{ }^{\circ} \mathrm{C}$ (para os concretos sem cimento) ou $350{ }^{\circ} \mathrm{C}$ (para as composições contendo CAC) por $5 \mathrm{~h} \mathrm{e}$, depois, a um último a $650^{\circ} \mathrm{C}$ por 5 h. Para os concretos contendo CAC foi feito tratamento térmico a $350{ }^{\circ} \mathrm{C}$ para garantir a eliminação da maior parte dos hidratos de cimento. A Fig. 9 mostra o teor de água eliminado em cada uma das temperaturas de secagem $\left(\mathrm{W}_{\mathrm{D}}\right)$. A $110{ }^{\circ} \mathrm{C}$ uma quantidade elevada de água é eliminada para todos os concretos, sendo que para as composições contendo CAC observa-se valores relativamente inferiores devido à hidratação do cimento.

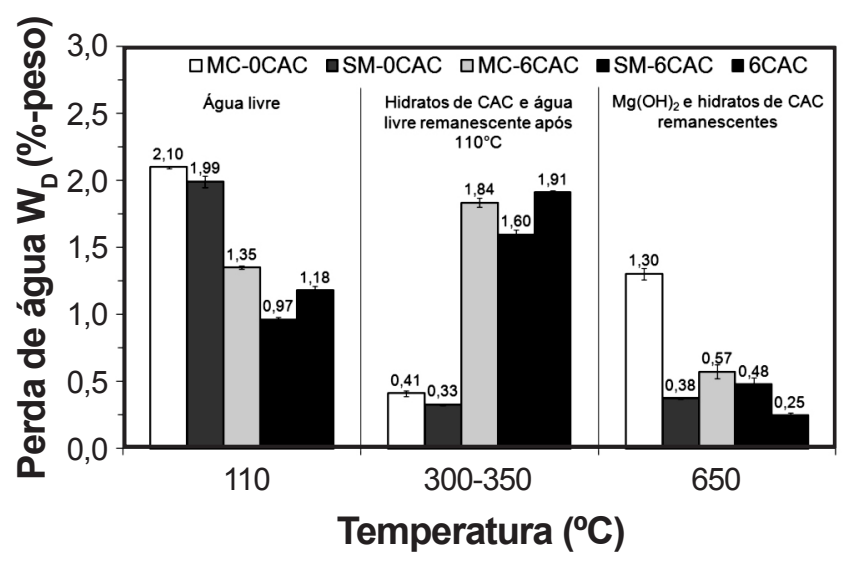

Figura 9: Teor de água removido $\left(\mathrm{W}_{\mathrm{D}}\right)$ após 1 dia de cura a $50{ }^{\circ} \mathrm{C}$ e após secagem a $110{ }^{\circ} \mathrm{C}, 300{ }^{\circ} \mathrm{C}$ ou $350{ }^{\circ} \mathrm{C}$ e $650{ }^{\circ} \mathrm{C}$ para os concretos sem cimento (MC-0CAC e SM-0CAC) e com cimento (MC-6CAC, SM-6CAC e 6CAC).

[Figure 9: Released water content $\left(W_{D}\right)$ after 1 day of curing at $50{ }^{\circ} \mathrm{C}$ and drying at $110{ }^{\circ} \mathrm{C}, 300{ }^{\circ} \mathrm{C}$ or $350^{\circ} \mathrm{C}$ and $650{ }^{\circ} \mathrm{C}$ for free-cement castables (MC-OCAC and SM-OCAC) and cementcontaining castables (MC-6CAC, SM-6CAC and 6CAC).]

Uma vez que para secagem em temperaturas menores que $350{ }^{\circ} \mathrm{C}$ não há a decomposição do hidróxido de magnésio [23] e a maior parte dos hidratos de cimento se decompõem $[3,19]$, a quantidade de água removida após o tratamento térmico a $300{ }^{\circ} \mathrm{C}$ (para os concretos sem CAC) e a $350{ }^{\circ} \mathrm{C}$ (para os concretos contendo cimento) pode ser atribuída principalmente à água livre remanescente nos concretos e aos hidratos de CAC (Fig. 9). Sendo assim, a água eliminada no tratamento a $650{ }^{\circ} \mathrm{C}$ pode ser associada principalmente à formação de brucita e à uma pequena quantidade de hidratos de CAC remanescentes. Para as formulações MC-6CAC e SM-6CAC, a perda de água associada aos hidratos de cimento foi de 1,84\%-p e 1,6\%-p, respectivamente, indicando que uma quantidade maior de hidratos de cimento foi formada para o concreto MC-6CAC devido ao teor mais elevado de água utilizado no processamento (5,9\%-p). Por outro lado, ao comparar as composições SM-6CAC e 6CAC, com mesmo teor de água (4,2\%-p), nota-se que para o concreto contendo $\mathrm{MgO}$ parte da água é consumida na hidratação da magnésia e, conseqüentemente, há formação de uma quantidade menor de hidratos de CAC, como indicam as perdas de água na Fig. 9 (1,6\%-p e 1,91\%-p, respectivamente). Para a avaliação da quantidade de brucita formada dois aspectos importantes devem ser considerados, o efeito da microssílica e do cimento de aluminato de cálcio. De acordo com a literatura, na presença de microssílica, uma camada protetora insolúvel de silicato de magnésio hidratado é formada na superfície 


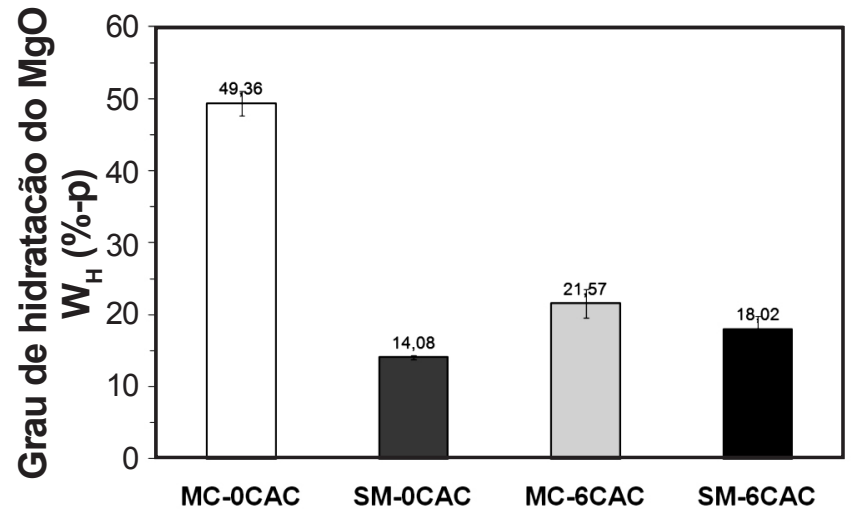

Figura 10: Grau de hidratação do $\mathrm{MgO}$ dos concretos após 1 dia de cura a $50{ }^{\circ} \mathrm{C}$ e após 1 dia de secagem a $110{ }^{\circ} \mathrm{C}$ para os concretos sem cimento (MC-0CAC e SM-0CAC) e com cimento (MC-6CAC e SM-6CAC).

[Figure 10: Castables' magnesia hydration after 1 day of curing at $50{ }^{\circ} \mathrm{C}$ and 1 day of drying at $110{ }^{\circ} \mathrm{C}$ for free-cement castables (MC-OCAC and SM-OCAC) and cement-containing castables (MC6CAC and $S M-6 C A C)$.

das partículas de $\mathrm{MgO}$, reduzindo-se assim sua velocidade de hidratação [9]. Por outro lado, a dissolução dos aluminatos de cálcio, durante a reação de hidratação do CAC, resulta em um aumento significativo do $\mathrm{pH}$ e da concentração de íons $\mathrm{OH}^{-}$no meio [24]. Conseqüentemente, devido ao princípio de deslocamento químico, em pH alcalino, a hidratação do sínter de $\mathrm{MgO}$ é favorecida [8, 10]. Para a magnésia cáustica, o pH do meio não é muito afetado pela adição de CAC, uma vez que esta fonte de $\mathrm{MgO}$ é muito mais reativa e causa um grande aumento do $\mathrm{pH}$ durante sua hidratação [8]. Utilizando a equação $\mathrm{G}$, a perda de água associada à brucita e aos hidratos de CAC remanescentes (Fig. 9) pode ser convertida no grau de hidratação da magnésia, como mostra a Fig. 10. De acordo com os cálculos, na presença de CAC o grau de hidratação da MC diminuiu cerca de $50 \%$ enquanto para o SM ocorreu um aumento de aproximadamente $22 \%$. Como a hidratação da MC não é significativamente afetada pela presença de CAC, o menor grau de hidratação observado pode ser atribuído à competição entre o CAC e o $\mathrm{MgO}$ pela água livre no meio e ao aumento da resistência mecânica associado à presença de cimento. Para o concreto contendo SM, apesar dos cálculos sugerirem que na presença de CAC ocorre a formação de uma quantidade maior de brucita, este resultado não pode ser atribuído ao efeito do cimento favorecendo a hidratação do sínter, pois os resultados de termogravimentria apresentados em seguida (Fig. 11) indicam que ocorreu o contrário. Tal resultado exemplifica a dificuldade de quantificar a hidratação do $\mathrm{MgO}$ na presença de cimento, uma vez que uma pequena quantidade de hidrato de CAC permanece na estrutura dos concretos após o tratamento térmico a $350^{\circ} \mathrm{C}$.

A hidratação da magnésia para os concretos foi ainda investigada por meio de ensaios de termogravimetria. As amostras foram primeiramente curadas durante 1 ou 7 dias a $50{ }^{\circ} \mathrm{C}$ e em seguida secas a $110{ }^{\circ} \mathrm{C}$ por $24 \mathrm{~h}$ para eliminação da água livre (exceto a composição MC-6CAC, com 1 e 3 dias de cura, pois após este período a amostra se desintegrou
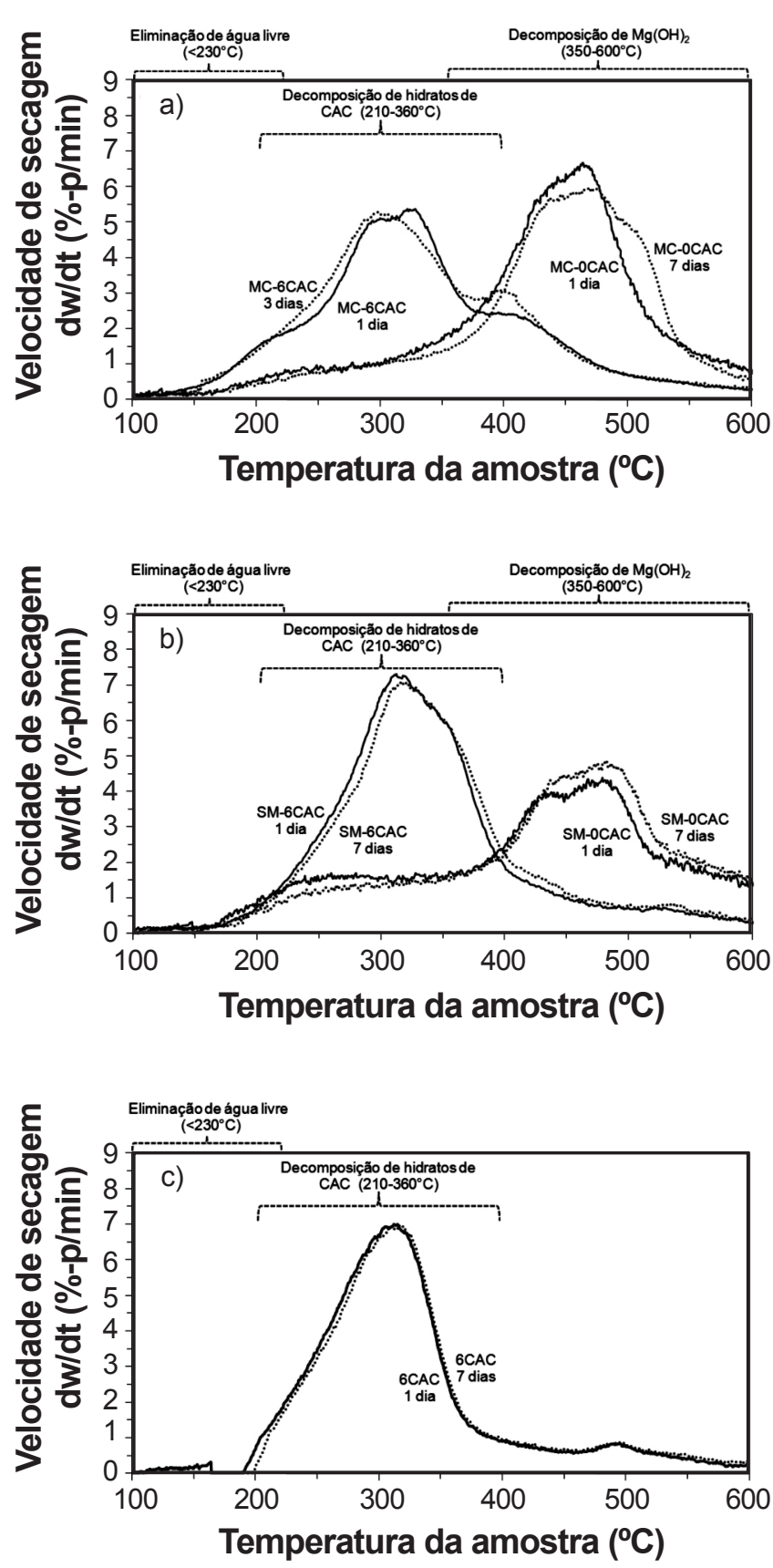

Figura 11: Velocidade de secagem em função da temperatura da amostra para diferentes períodos de cura (1 dia e 7 dias) e após 1 dia de secagem a $110^{\circ} \mathrm{C}$. a) concretos contendo $\mathrm{MC}$, sem cimento (MC-0CAC) e com cimento (MC-6CAC); b) concretos contendo $\mathrm{SM}$, sem cimento (SM-0CAC) e com cimento (SM-6CAC); c) concreto contendo cimento e sem $\mathrm{MgO}$ (6CAC).

[Figure 11: Drying rate profiles as a function of sample's temperature for different curing times (1 day and 7 days) and after 1 day of drying at $110{ }^{\circ} \mathrm{C}$. a) MC-containing castables without cement (MC-OCAC) and with cement (MC-6CAC); b) SMcontaining castables without cement (SM-OCAC) and with cement (SM-6CAC); c) cement-containing castable without $\mathrm{MgO}(6 C A C)$.]

durante a secagem). As Figs. 11 e 12 apresentam os resultados obtidos quanto à velocidade de secagem e à perda de massa durante a secagem. As curvas da velocidade de secagem em 
função da temperatura para concretos contendo CAC e $\mathrm{MgO}$ normalmente são constituídas por dois picos principais: o primeiro, abaixo de $360{ }^{\circ} \mathrm{C}$, relacionado à decomposição dos hidratos do CAC $[3,19,23]$ e o segundo, acima de $350{ }^{\circ} \mathrm{C}$, devido à decomposição do hidróxido de magnésio [3, 23]. O pico associado à desidratação do cimento pode ser atribuído aos hidratos $\mathrm{AH}_{3}\left(\mathrm{Al}_{2} \mathrm{O}_{3} \cdot 3 \mathrm{H}_{2} \mathrm{O}\right)$ e $\mathrm{C}_{3} \mathrm{AH}_{6}\left(3 \mathrm{CaO} \cdot \mathrm{Al}_{2} \mathrm{O}_{3} \cdot 6 \mathrm{H}_{2} \mathrm{O}\right)$, normalmente formados quando a cura é realizada acima de $35^{\circ} \mathrm{C}$, e que se decompõem entre $210-300{ }^{\circ} \mathrm{C}$ e $300-360{ }^{\circ} \mathrm{C}$, respectivamente [21]. Para os concretos sem CAC (0CAC, Figs. 11a e b), os picos de decomposição do $\mathrm{Mg}(\mathrm{OH})_{2}$ são claramente observados e as taxas são elevadas, indicando que, para estas composições, ocorre a formação de uma quantidade maior de hidróxido, uma vez que a área abaixo dos picos é proporcional a quantidade de hidratos formados. $\mathrm{Na}$ presença de cimento, pode ocorrer uma sobreposição entre os picos de decomposição dos hidratos do CAC e da brucita, dificultando a observação do pico relacionado ao hidróxido de magnésio, principalmente quando a quantidade de $\mathrm{Mg}(\mathrm{OH})_{2}$ formada é pequena, como para o concreto SM6CAC. Para a composição SM-0CAC mesmo após a secagem a $110{ }^{\circ} \mathrm{C}$ uma pequena quantidade de água permaneceu na estrutura do concreto, como indica o pico abaixo de 300 ${ }^{\circ} \mathrm{C}$. O pico de decomposição dos hidratos de CAC pode ser observado aproximadamente entre 210 e $360^{\circ} \mathrm{C}$ para todos os concretos (Fig. 11a-c). Apesar da decomposição da gibbsita $\left(\mathrm{AH}_{3}\right)$ normalmente ocorrer no intervalo $210-300{ }^{\circ} \mathrm{C}$, durante a desidratação este hidrato de cimento pode também se converter para boehmita $(\mathrm{AH})$, que por sua vez se decompõe entre $450{ }^{\circ} \mathrm{C}$ e $550{ }^{\circ} \mathrm{C}$ [21]. Sendo assim, para o concreto $6 \mathrm{CAC}$, o pico de decomposição observado próximo a $500{ }^{\circ} \mathrm{C}$ pode ser atribuído à presença de boehmita (Fig. 11c).

Além dos hidratos de cimento e da brucita para a composição MC-6CAC pode ter sido formado um composto conhecido como hidrotalcita $\left(\mathrm{Mg}_{6} \mathrm{Al}_{2} \mathrm{CO}_{3}(\mathrm{OH})_{16} \cdot 4 \mathrm{H}_{2} \mathrm{O}\right)$ [2528]. A hidrotalcita é formada por camadas de hidróxido de alumínio e magnésio separadas por uma região inter-lamelar, que contém moléculas de água e diferentes ânions. Sua geração ocorre quando alguns dos íons $\mathrm{Mg}^{2+}$ da brucita são substituídos por $\mathrm{Al}^{3+}$ resultando em uma folha de octaedros carregada positivamente, cuja neutralidade é mantida por meio dos ânions inter-lamelares [25, 26]. A expansão causada pela formação de hidrotalcita pode ser ainda maior que da brucita, uma vez que sua densidade é menor $\left(\varrho_{\text {Brucita }}=2,54\right.$ $\mathrm{g} / \mathrm{cm}^{3}$ e $\varrho_{\text {Hidrotalcita }}=2,18 \mathrm{~g} / \mathrm{cm}^{3}$ ) e possui maior espaçamento inter-lamelar ( $\mathrm{h}_{\text {Brucita }}=3,4 \AA$ e $\mathrm{h}_{\text {Hidrotalcita }}=23 \AA$ ) $[25,26]$. Mas sua formação é favorecida somente quando a razão de íons $\mathrm{Mg}^{2+} / \mathrm{Al}^{3+}$ é igual a 3:1 ou 2:1 [27]. No caso do concreto MC6CAC, onde a proporção $\mathrm{CAC} / \mathrm{MgO}$ é de 1:1, este composto pode ocorrer apenas em pequenas quantidades [8]. Como ocorre uma concentração maior de íons $\mathrm{Mg}^{2+}$ na superfície das partículas de $\mathrm{MgO}$, a hidrotalcita pode ser formada como um filme recobrindo as partículas de magnésia, o que dificulta a hidratação posterior $[8,28]$, pois a hidrotalcita apresenta baixa solubilidade. Além disto, sua decomposição normalmente é observada em intervalos próximos aos de decomposição dos hidratos de CAC. Primeiramente (próximo a $220{ }^{\circ} \mathrm{C}$ ), há a
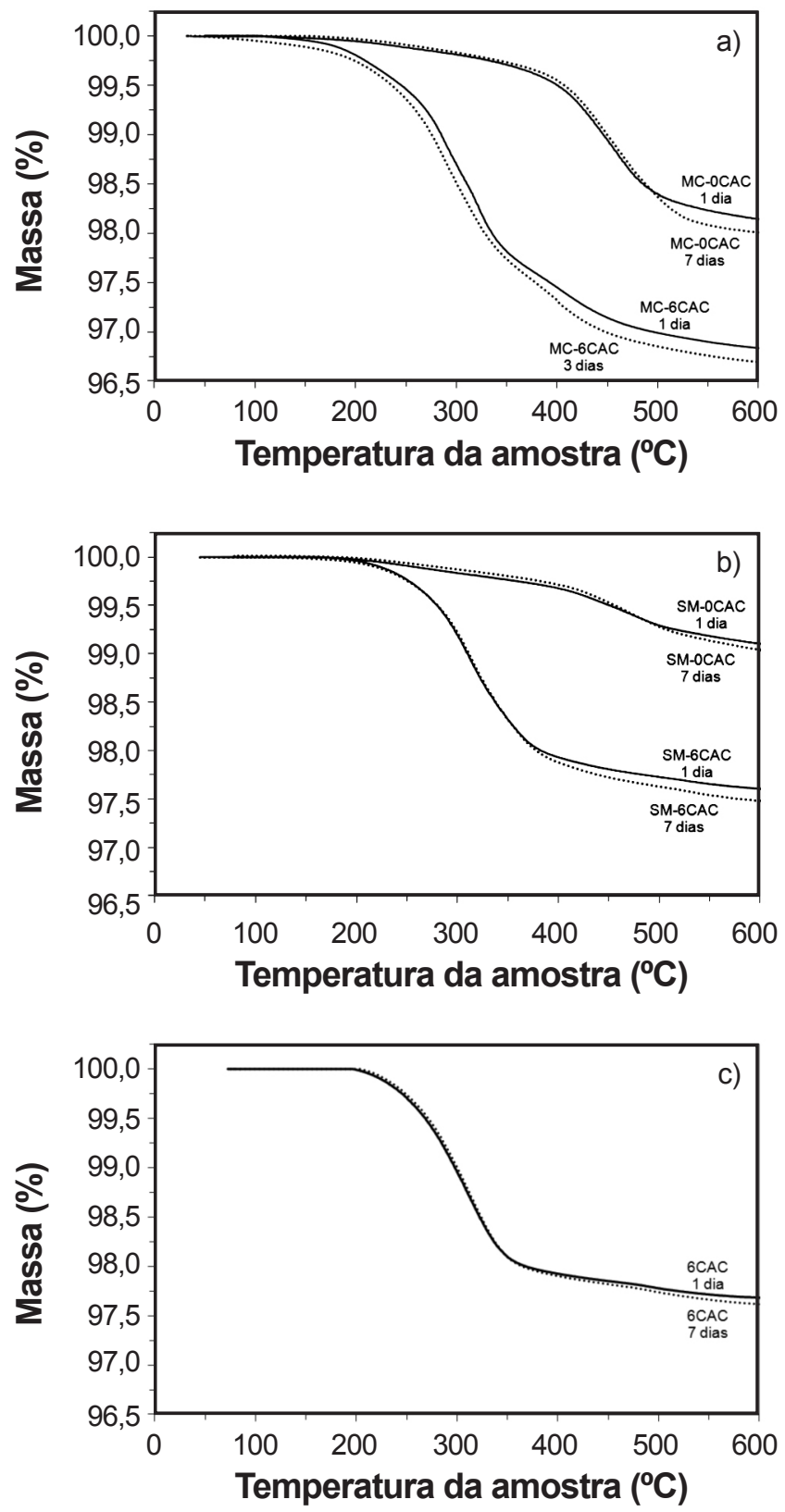

Figura 12: Perda de massa em função da temperatura da amostra para diferentes períodos de cura (1 dia e 7 dias) e após 1 dia de secagem a $110^{\circ} \mathrm{C}$. a) concretos contendo MC, sem cimento (MC0CAC) e com cimento (MC-6CAC); b) concretos contendo SM, sem cimento (SM-0CAC) e com cimento (SM-6CAC); c) concreto contendo cimento e sem $\mathrm{MgO}$ (6CAC).

[Figure 12: Mass loss curve profiles as a function of sample's temperature for different curing times ( 1 day and 7 days) and after 1 day of drying at $110{ }^{\circ} \mathrm{C}$. a) MC-containing castables without cement (MC-OCAC) and with cement (MC-6CAC); b) SMcontaining castables without cement (SM-OCAC) and with cement (SM-6CAC); c) cement-containing castable without $\mathrm{MgO}(6 C A C)$.]

perda da massa associada à água interlamelar e, em seguida $\left(360{ }^{\circ} \mathrm{C}\right)$, a perda de massa devido aos grupos $\mathrm{OH}^{-}$e $\mathrm{CO}_{3}{ }^{2+}$ [29]. Entre 1 e 7 dias de cura não são observadas diferenças significativas em relação a hidratação da magnésia e do cimento nas curvas de velocidade de secagem, como 
mostram as Figs. 11a-c. Por outro lado, nota-se um pequeno aumento na perda de massa entre o primeiro e o sétimo dia de cura (Fig. 12), indicando que uma quantidade adicional de brucita e hidratos de CAC foi formada após o primeiro dia. Neste caso, a hidratação da magnésia provavelmente ocorreu apenas nos contornos de grão. Para a MC, que possui menor tamanho de cristais, e, conseqüentemente, partículas com maior densidade de defeitos e elevada área superficial, a hidratação foi superior.

\section{CONCLUSÕES}

O acompanhamento do módulo elástico (MOE) utilizando o método de ressonância de barras apresentou-se como uma técnica eficiente para a avaliação da hidratação do $\mathrm{MgO}$ em concretos refratários durante a cura. Em relação às medidas de resistência mecânica (obtidas por compressão diametral), o MOE permite determinar de forma mais precisa a evolução da microestrutura do concreto em função do tempo de cura, com a vantagem de ser ainda um método não-destrutivo. Adicionalmente, o MOE apresentou desvio padrão muito menor e permitiu a detecção prévia do início da formação de trincas durante a cura em comparação com outras técnicas como a resistência mecânica e a expansão volumétrica aparente. A evolução do MOE durante a cura para os concretos contendo diferentes fontes de $\mathrm{MgO}$ apresentou dois comportamentos distintos, que estão relacionados à ocorrência de danos devido à expansão causada pela formação da brucita e à habilidade da estrutura de acomodar adequadamente a expansão. Para as composições contendo MC o acompanhamento do módulo elástico também indicou que o aumento da rigidez associado ao CAC atrasa o início dos danos devido à hidratação da magnésia. Na etapa de secagem uma redução do módulo elástico foi observada para as composições contendo MC devido à formação de trincas, enquanto ocorreu aumento na resistência mecânica. Tal resultado ressalta a importância da utilização do módulo de Young para a detecção de danos causados pela hidratação da magnésia que não podem ser observados visualmente. Sendo assim, a avaliação in situ da evolução do MOE em função do tempo e da temperatura de secagem pode revelar aspectos relevantes sobre a hidratação da magnésia em temperaturas intermediárias (até $800^{\circ} \mathrm{C}$ ), algo que já está sendo avaliado pelos autores.

\section{AGRADECIMENTOS}

Os autores agradecem à Magnesita Refratários S.A., FAPESP e CNPq pelo apoio dado ao trabalho.

\section{REFERÊNCIAS}

[1] A. Kitamura, K. Onizuka, K. Tanaka, Taikabutsu Overseas 16, 3 (1995) 3-11.

[2] A. Kaneyasu, S. Yamamoto, A. Yoshida, Taikabutsu Overseas 17, 2 (1996) 21.

[3] R. Salomão, L. R. Bittencourt, V. C. Pandolfelli, Ceram.
Int. 33, 5 (2007) 803-810.

[4] A. Nishikawa, Tokyo: Technical Report No. 33-7, Plibrico Japan Co. Ltd. (1984) 98-101.

[5] A. Yoschida, T. Nemoto, A. Kaneyasu, Proc. Unified Int. Tech. Conf. Refractories, UNITECR'03, Osaka, Japan (2003) 433-436.

[6] R. Salomão, L. R. Bittencourt, V. C. Pandolfelli, Cerâmica 52, 322 (2006) 146-150.

[7] V. S. S. Birchal, S. D. F. Rocha, V. S. T. Cimineli, Minerals Eng. 13, 14-15 (2000) 1629-1633.

[8 ] R. Salomão, L. F. Amaral, V. C. Pandolfelli, Anais $52^{\circ}$ Cong. Bras. Cerâmica, Florianópolis, SC (2008).

[9] R. Salomão, V. C. Pandolfelli, Cerâmica 54, 329 (2008) 43-48.

[10] R. Salomão, V. C. Pandolfelli, Ceram. Int. 35 (2009) 3117-3124.

[11] A. Boumiz, C. Vernet, Cohen Tenoudji, Adv. Cem. Based Mater. 3 (1996) 94-106.

[12] R. C. Bradt, Key Eng. Mater. 88 (1993) 165-192.

[13] G. B. Cintra, M. A. L. Braulio, M. A. M. Brito, L. R. M. Bittencourt, V. C. Pandolfelli, Cerâmica 54, 331 (2008) 287-295.

[14] C. D. Parr, H. Fryda, R. Roesky, Proc. Unified Int. Tech. Conf. Refractories, UNITECR'01, Berlim, Alemanha (2001) 1633-1649.

[15] W. M. Silva, A. E. M. Paiva, E. L. G. Villaboim, M. D. M. Innocentini, J. A. Rodrigues, V. C. Pandolfelli, Cerâmica 49, 311 (2003) 141-145.

[16] P. Lauzon, J. Rigby, C. Oprea, T. Troczynski, G. Oprea, Proc. Unified Int. Tech. Conf. Refractories, UNITECR'03, Osaka, Japan (2003) 54-57.

[17] G. Pickett, Proc. Am. Soc. Testing Mater. 45 (1945) 846-865.

[18] R. Salomão, V. C. Pandolfelli, Proc. Unified Int. Tech. Conf. Refractories, UNITECR'09, Salvador, Brazil (2009) 56.

[19] M. D. M. Innocentini, F. A. Cardoso, M. M. Akyioshi, V. C. Pandolfelli, J. Am. Ceram. Soc. 86, 7 (2003) 1146-48. [20] M. A. L. Braulio, D. H. Milanez, E. Y. Sako, L. R. M. Bittencourt, V. C. Pandolfelli, Proc. Unified Int. Tech. Conf. Refractories, UNITECR'07, Dresden, Alemanha (2007) 540-543.

[21] W. E. Lee, W. Vieira, S. Zhang, K. Ghanbari Ahari, H. Sarpoolaky, C. Parr, Inter. Mat. Ver. 46, 3 (2001) 145-167.

[22] F. T. Ramal J., R, Salomão, V. C. Pandolfelli, Refrac. Appl. 10, 3 (2005) 10-13.

[23] R. Salomão, V. C. Pandolfelli, Cerâmica 54, 330 (2008) 145-151.

[24] J. R. Garcia, I. R. de Oliveira, V. C. Pandolfelli, Cerâmica 53, 325 (2007) 42-56.

[25] R. Reichle, Chemtech 16 (1986) 58-63.

[26] A. Vaccari, Appl. Clay Sci. 14, 4 (1999) 161-198.

[27] G. W. Brindley, S. Kikkawa, Am. Mineral. 64 (1979) 836-843.

[28] G. Ye, T. Troczynsky, Ceram. Int. 32, 3 (2006) 257-262.

[29] K. G. Ahari, J. H. Sharp, W. E. Lee, J. Eur. Ceram. Soc. 22 (2002) 495-503.

(Rec.03/05/2010, Ac. 13/08/2010) 